\title{
Why epistemology matters
}

\author{
Archie L Dick \\ University of Pretoria
}

\begin{abstract}
Epistemology is traditionally devoted to the study of the justification or the evaluation of the beliefs we have on the basis of some given body of evidence. Epistemology in library and information studies questions its assumptions and methods in order to test the reliability of its knowledge claims and to eliminate false claims and errors in models and theories.
\end{abstract}

\section{Keywords}

Epistemology, library and information studies, indigenous knowledge, information seeking and retrieval

Corresponding author

Archie L Dick, Professor, Department of Information Science, University of Pretoria, Lynnwood Road, Pretoria, Republic of South Africa, 0002.

archie.dick@up.ac.za

What counts as credible evidence on information seeking patterns in the small, medium and micro enterprise (SMME) sector in Namibia? Which data gathering instruments guarantee valid findings on the use of electronic resources by students at universities in India? How can bias be corrected in a classification scheme that regards indigenous knowledge as inferior to Western conceptions of knowledge?

These questions: 
- Are related in one or another way with epistemology in library and information studies (LIS);

- Show that there can be no single way of knowing the multiple realities of LIS; and

- Ask how LIS professionals and researchers can know things that involve their everyday practices, and that shape their information tools, policies, and research strategies.

The social status of LIS professionals, the claims they make, the research they produce, and the advice they offer are supported by a knowledge base. Epistemology in LIS concerns itself with this knowledge base. Questioning the assumptions about valid knowledge and realities that are hidden from view in a selection policy, a classification scheme, an information seeking and retrieval model, or a research methodology is the task of epistemology in LIS. Decisions about the truth or falsity of these assumptions make real differences to what materials are selected for a library, and how they are arranged for interpretation and use, as well as the credibility of research findings and policy decisions.

Epistemology or the theory of knowledge is a branch of philosophy concerned with a general treatment of the nature, origins, scope and limits of human knowledge, its presuppositions and bases, and investigates the methods by which it is acquired (Hamlyn 1967; Coffey 1917). Epistemology is traditionally devoted to the study of the justification, or, more generally, the evaluation of the beliefs we have on the basis of some given body of evidence (Hintikka 1992). A central focus on human knowledge is what distinguishes epistemology as an area of interest, and the several perspectives of 
the nature, origins and general reliability of claims to knowledge distinguish epistemological positions from each other.

Two central questions that epistemology in LIS seeks to answer are:

- How much of what the discipline of LIS claims to know on the basis of its modes of professional practice and its research traditions can indeed be justified on the basis of evidence for those claims?; and

- What type of knowledge is 'bibliothecal knowledge', or what Kevin McGarry (1985) calls the 'special kind of knowing' in LIS.

Significant for LIS professionals and researchers is that the intentional or unconscious espousal of an epistemology or epistemological position (used interchangeably here) holds definite implications for how they practice their profession, and conduct research (Harding 1988). Why a specific epistemology in LIS may be dominant at any given time cannot be fully explained, but it may have something to do with the prevailing intellectual climate. Its alliance with other powerful social forces makes it appear natural, inevitable, and unchallengeable.

In fact there are competing epistemologies that co-exist in tension with each other at any given time. There is an essential tension between the broad scientific and hermeneutic epistemological traditions in LIS. The scientific tradition primarily implies positivist epistemologies, and the hermeneutics tradition generally implies constructivist epistemologies. Criticism of positivist epistemologies in LIS often ignores their value, and fails to consider other equally useful epistemological positions. Alternative epistemologies, on the other hand, tend to emphasize their conflicts with positivism instead of developing potential applications. 
It is more helpful to recognize that there are multiple realities in LIS as evidenced by its historical features of wholeness and interconnectedness. From ancient libraries found at Nineveh, Hattushash and Alexandria to modern national, university, and public libraries, there is a consistent effort in LIS to deal with the entire corpus of recorded human knowledge. This feature of LIS was recognized and formalized in the work of scholars like Paul Otlét (1868-1944) and Hénri La Fontaine (1854-1943). They addressed themselves to the task of organizing the world's knowledge in the form of a classified central card catalog of the literature, illustrations, and institutions of all countries, ages, and languages (Arntz 1974).

The range of epistemological positions required to deal with the multiple realities of LIS generate a number of intellectual and theoretical issues that can result in debate and discussion. This self-reflexive character of epistemology in LIS questions its own assumptions and methods in order to test the reliability of its knowledge claims and to eliminate false claims and errors in models and theories. Epistemology can explain, for example, how models of information seeking and retrieval (IS\&R) can transfer cultural bias into their local applications (Dick 2006). A case in point is the socio-cultural bias of the cognitive approach used in Peter Ingwersen and Kalervo Järvelin's (2005) nested model of context stratification for information seeking and retrieval (IS\&R).

Epistemology, in this case asks: 'Whose model'? and 'What context'? These questions involve the politics and economics of LIS model and theory production in developed Northern hemisphere countries, and their consumption in developing Southern hemisphere countries. They also involve issues of epistemology. The criticisms of individualism and non-sociality of the cognitive epistemological approach, 
for example, should be met when this model is applied in contexts where other values are considered more important.

The cognitive viewpoint, according to Talja (1997), offers 'no concrete and obvious solutions to the question of how to conceptualize and study the socio-cultural context of information processes'. This is borne out in Ingwersen and Järvelin's description of an information seeker acquiring information from 'man-made' signs in natural settings, as a component of the IS\&R model. This process is called the 'Okawango Pursuit' and it draws on the observations of European tourists to the Okavango Delta, near the Kalahari Desert in the south-western region of Africa. The information seeker is a local African tour guide whose boat falls behind another that is leading the way on a boat safari. The tourists are surprised at how quickly the tour guide is able to negotiate the maze of waterways, and to catch up by detecting things like wet reeds caused by the leading boat, and by the direction of water lilies.

Incredibly though, this opportunity for the cognitive approach to explore the sociocultural contexts of the local African tour guide's information acquisition is completely overlooked. Instead, the tour guide's intellectual processes are disappointingly described in terms of the testing and verification of hypotheses relating to Karl Popper's (1969) three-world ontology and epistemology. The role of context in individual cognition that the authors postulate in their model as a principle of complementary social and cognitive influence is not used to explain how the African cultural environment and information space influence the way that the tour guide acquires information.

Instead, individualism and non-sociality is affirmed in the description of how the tour guide sets about seeking and acquiring the information that he needs to find his way 
back to the leading boat. Explanations by the local tour guide himself about wet reeds and turned water lilies would, however, more effectively be sought in what is called indigenous knowledge, understood as any knowledge held collectively by a group and that informs its interpretation of the world. This is not inconsistent with De Mey's founding idea for the cognitive approach that people effectively process information using a model of their world (de Mey 1980).

It is therefore the world of the local tour guide and not the world of the tourists that would best explain his cognitive processes. Popper's epistemology is not the appropriate explanatory model for how information is sought or stored and retrieved by the African tour guide. Whereas Popper requires the storage of all knowledge in books, libraries, and other physical formats, the epistemology of indigenous knowledge regards knowledge storage as insufficient and even detrimental for the process of knowledge generation (Reagon 2005).

This is not to make a paternalistic or racist point that the African tour guide does not share the cognitive capacity and skills of the tourists. Instead, the point is that his own world shapes the way he uses signals from nature, and is best explained and understood in those terms. There is, in other words, an alternative way of knowing and constructing reality at work in indigenous knowledge. Until this IS\&R model recognizes and accommodates this alternative epistemology, cultural bias will persist. Individual information seekers will be viewed in terms of abstract concepts that are considered valid for all information seekers, regardless of their geographical and socio-cultural contexts. 
We will become better LIS professionals and researchers when we are aware that our epistemological attitudes influence how we practice our profession and conduct our research.

\section{References}

Arntz, H (1974). International Federation for Documentation (FID). In Kent, A. et al Encyclopedia of library and information science, vol.12. New York: Marcel Dekker: 377402.

Coffey, P (1917) Epistemology or the theory of knowledge: an introduction to general metaphysics. London: Longmans.

De Mey, M (1980) The relevance of the cognitive paradigm for information

Science. In Harbo, O. (ed.), Theory and application of information research. London: Mansell: 48-61.

Dick, A L 2006 Whose model, what context?: Cultural bias and the nested model of context stratification for information seeking and retrieval: Available at:

http://www.ifla.org/IV/ifla72/papers/145-Dick-en.pdf. (Accessed 14 November 2012). Hamlyn, D W (1967) Epistemology, history of. In Edwards, P. (ed.), Encyclopedia of philosophy, vol. 3. New York: Macmillan: 8-38.

Harding, S (1988) Practical consequences of epistemological choices. Culture and Cognition, 21: 153-155.

Hintikka, J (1992) Knowledge-seeking by questioning. In Dancy, J. and Sosa, E. (eds.), A companion to epistemology. Oxford: Blackwell: 239-244).

Ingwersen, P and Järvelin, K (2005) The turn: integration of information 
seeking and retrieval in context. Dordrecht: Springer.

McGarry, K J (1985) The future has already begun. Library Association Record, 87: 97.

Popper, Karl R (1969) Conjectures and refutations: the growth of scientific knowledge.

London: Routledge \& K. Paul.

Reagon, T (2005) Non-western educational traditions: indigenous approaches to

educational thought and practice. Mahwah, N.J.: Lawrence Erlbaum.

Talja, S (1997) Constituting 'Information' and 'User' as research objects: a theory of

knowledge formations as an alternative to the information man-theory. In Vakkari, P. et al (eds.), Information seeking in context London: Taylor Graham: 67-80. 